\title{
A VIOLÊNCIA DISCUTIDA NA EDUCAÇÃO BÁSICA: O MALLEUS MALEFICARUM COMO DOCUMENTO HISTÓRICO
}

\author{
DISCUSSED VIOLENCE IN BASIC EDUCATION: \\ THE MALLEUS MALEFICARUM AS DOCUMENT HISTORY
}

João Davi Avelar Pires ${ }^{1}$

\begin{abstract}
RESUMO: Pretendemos, neste trabalho, propor a utilização da obra Malleus Maleficarum nas aulas de História na Educação Básica. Entendemos os conceitos de utilização e documento histórico como uma tentativa de aproximar os alunos do fazer historiográfico, do trabalho do historiador, tendo em mente as diversas possibilidades que esta prática nos oferece. Dessa forma, o contato com o documento, no caso deste trabalho o Malleus Malleficarum, escrito por inquisidores em 1484, torna possível a abordagem de diversas temáticas, como a Inquisição e a violência aplicada contra as mulheres neste período; a construção do imaginário e das representações sociais sobre o corpo feminino e sobre a mulher; e também a perseguição religiosa criada e estimulada pela intolerância e desvalorização do outro. Traçamos, neste trabalho, breves discussões sobre as mudanças ocorridas no Ensino de História e que nos dá espaço para este tipo de trabalho documental, assim como apresentamos as possibilidades e as abordagens possíveis da obra em questão, o Malleus Maleficarum.
\end{abstract}

Palavras-chave: História e Ensino. Malleus Maleficarum. Violência. Inquisição.

\begin{abstract}
We intend in this paper propose the use of the work Malleus Maleficarum in history lessons in Basic Education. Understand and use the concepts of historical document as an attempt to bring the students to historiography, the historian's work, bearing in mind the various possibilities that this practice offers. Thus, contact with the document, in the case of this work the Malleus Malleficarum, written by inquisitors in 1484, makes it possible to approach different topics, such as the Inquisition and applied violence against women in this period, the construction of the imaginary and the representations labor on the female body and the woman, and also religious persecution created and stimulated by intolerance and belittle others. We trace this work, brief discussions about the changes in the History Teaching and that gives us space for this kind of documentary work as well as present the possibilities and possible approaches of the work in question, the Malleus Maleficarum.
\end{abstract}

Keywords: History and Education. Malleus Maleficarum. Violence. Inquisition.

\footnotetext{
${ }^{1}$ Mestrando em História Social na Unviersidade Estadual de Londrina. Professor da rede pública de ensino.
}

História \& Ensino, Londrina, v. 19, n. 1, p. 247-261, jan./jun. 2013 


\section{Introdução}

O presente trabalho propõe a utilização em sala de aula, da obra Malleus Maleficarum, escrita em 1484, pelos dominicanos Heinrich Cramer e James Sprenger. Como manual para os inquisidores, serviu de guia teórico e prático para a ação inquisitorial em toda sua duração. Tendo por base a influência do Malleus Maleficarum para a construção da imagem da mulher e de suas fragilidades relacionadas à sexualidade e ao corpo, da aplicação da violência como método institucional de interrogatório, propomos que a obra seja utilizada como fonte e documento histórico nas salas de aula. Assim, apresentamos a obra como um ponto de partida para o estudo da Inquisição e das perseguições religiosas deste período, visando a compreensão das práticas de violência empreendidas, suas finalidades e também a desconstrução e reelaboração de algumas ideias positivas sobre a violência, apresentadas por alguns alunos.

Optamos, neste trabalho, a seguir a seguinte trajetória. Num primeiro momento, nos referimos a questões ao interesse manifesto pelos alunos em relação ao tema da violência e às mudanças ocorridas na historiografia e no Ensino de História nas últimas décadas. Em seguida, discutimos brevemente o período inquisitorial, ou seja, o contexto e momento de gestação da obra Malleus Maleficarum, e por último, a proposta de inserção da violência como tema de Ensino na Educação Básica e exploração, como documento, do Malleus Maleficarum.

É comum para nós, professores, encontrarmos um grande interesse por parte dos alunos em assuntos relacionados à violência. Atualmente, ela aparece com freqüência na mídia e na indústria cultural, em filmes, novelas, jogos de computador, videogames, músicas, entre outros. Na mídia, muitas vezes são apresentadas situações onde a violência é empregada para o "bem", ou seja, é retratada como tendo bom uso. Assim, os alunos estão em contato constante, mesmo que indireto, com a violência, o que pode figurar como uma das causas do interesse manifesto por eles.

Para que a temática da violência seja trabalhada de forma satisfatória na Educação Básica e na disciplina de História, é necessário que se leve em conta, 
além desse interesse, as ideias prévias dos alunos. Principalmente porque a observação no dia a dia da sala de aula indica que boa parte dos alunos não expressa repulsa pelas práticas de violência. Por outro lado, essas exercem fascínio, como se o violento e o torturador fossem pessoas corajosas, ousadas e com poder de mando.

A violência pode ser, obviamente, uma forma desumana de submissão ou de castigo infligido a indivíduos ou animais, mas, é comum encontrarmos na sala de aula visões e abordagens favoráveis ao se uso em casos específicos. Como exemplo, citamos as discussões sobre o tema que ocorrem em algumas de nossas aulas. Muitos alunos demonstram posições favoráveis ou neutras em relação à sua utilização. Neutralidade no sentido de não incomodar-se com práticas de violência sofridas, por exemplo, por assassinos, pedófilos, estupradores e criminosos em geral. Podemos inferir que, devido à carência ou até mesmo ausência de punições adequadas a determinados criminosos, a aceitação da violência como critério último de punição pode ser generalizada à sociedade, não somente aos alunos.

Dentro deste contexto, onde a violência causa fascínio, enquadramos o objetivo deste trabalho, a exploração de excertos do Malleus Maleficarum, não só para a discussão da violência e do período inquisitorial, mas também como uma tentativa de desconstrução das posturas favoráveis à sua utilização.

Assim, justificamos a importância dada por este trabalho ao estudo das práticas de violência, pois contribui para a formação humana dos jovens, na medida em que a História localiza tais práticas, identifica e analisa o contexto na qual ela acontece e quais os interesses e discursos envolvidos. Contribui também para a desconstrução de algumas posturas positivas - como já dissemos - que os alunos possuem sobre o uso da violência. O trabalho com as fontes históricas, o Malleus Maleficarum, permite ao aluno um contato mais direto com o objeto de discussão, incentivando seu interesse pela temática abordada e possibilitando uma maior compreensão.

Partimos do princípio de que a violência e suas manifestações podem ser consideradas um tema do Ensino de História na Educação Básica, mas, faz-se necessário enquadrar esta abordagem dentro de algumas vertentes teóricas. Para Marc Bloch (2002), a História é a ciência que lida com a ação dos homens 
no tempo. Logo, tudo pode ser considerado objeto da História, desde que a ação do homem possa ser ali percebida. Assim, as práticas de violência enquanto forma de subjugação, poder e controle, se fazem dignas de uma análise histórica e também de discussões no Ensino de História.

A partir da década de $1970^{2}$, o Ensino de História tem passado por várias transformações. Os grandes acontecimentos, os grandes personagens, reis, revolucionários e imperadores foram cada vez mais dando espaço a sujeitos antes esquecidos, como as classes mais pobres, as mulheres, os negros, os homossexuais, os operários, entre outros. Houve também a abertura de possibilidades para se estudar outros tipos de documentos que não os "oficiais", que retratavam somente os "grandes homens".

O aluno, que antes era entendido como um receptor passivo e sem participação no processo construtor do conhecimento, passa a ser agente fundamental do processo do conhecimento, que se dá através das relações e interações entre professor e aluno, buscando desenvolver a consciência crítica e a capacidade de reflexão. Neste novo cenário, se faz necessário a criação de pontes entre as temáticas abordadas e as situações cotidianas vivenciadas pelo aluno, buscando identificações com o tema da aula. Consideramos como imprescindível a criação de estratégias de ensino que partam de novas abordagens metodológicas, incluindo a problematização do conhecimento e da própria disciplina História, para que a formação dos cidadãos aconteça de maneira realmente crítica.

\section{A Inquisição}

De acordo com Gonçalves (2009), a organização da Inquisição acontece entre os anos de 1184-1229, e a imagem da bruxa vai sendo construída e

\footnotetext{
2 Os trabalhos nacionais desta década foram influenciados pela redemocratização brasileira, momento muito rico, onde o partido vencedor, PMDB, passou a investir na educação e se organizaram novas propostas curriculares, dando mais visibilidade as pesquisas sobre o Ensino. Os pesquisadores buscaram na História Nova Francesa os referenciais para sua produção. Na última década, os trabalhos sobre o Ensino de História concentram-se, basicamente, nas narrativas dos alunos, no conhecimento prévio e na maneira como eles relacionam um novo conhecimento com o que já possuem.
} 
difundida durante a Baixa Idade Média. Nos séculos XV e XVI, todo o processo gerador da misoginia irrompe em um grande genocídio, promovido pelos tribunais da Santa Inquisição, cujo objetivo era extirpar a ameaça das heresias e dos hereges, tanto realizadas por homens quanto por mulheres, os que, de variadas formas, não se adequavam aos padrões religiosos e morais da sociedade europeia ocidental. As primeiras bulas papais não faziam distinção de gênero ao fomentarem a repressão, mas, a maior parte das vítimas era constituída pelo sexo feminino e por membros das classes populares. 0 discurso do Tribunal do Santo Ofício foi fundamental para que a Igreja alcançasse tanto poder, nas esferas cultural, econômica e política.

Grande parte dessas perseguições era baseada na crença da existência da bruxaria e de que essas práticas eram maléficas tanto para as vítimas quanto à própria bruxa. É interessante destacar que, ao tentar categorizar e sistematizar as práticas hereges, a Igreja e os inquisidores estavam realizando uma tradução e interpretação de crenças estranhas a eles para algo mais compreensível (GINZBURG, 1991).

Em linhas gerais, o padrão de comportamento feminino na Idade Média era determinado por didáticos cristãos, como Santo Agostinho e São Tomás de Aquino. Baseados na interpretação sobre as Sagradas Escrituras, eram eles quem ditavam as normas de comportamento e procedimento da mulher no âmbito social, que basicamente era o familiar. Cria-se assim, a oposição entre as mulheres que não se guiam pelos moldes impostos pela Igreja e as mulheres que suplantaram suas más tendências naturais ligadas à carne e se fizeram santas. Percebemos neste último grupo de mulheres, a influência da imagem de Maria Madalena, como uma mulher carnal redimida pela religião. Assim, nem todas as mulheres se entregavam às práticas mágicas e de bruxaria, uma parte delas, mesmo que pequena, conseguia se livrar dos enlevos da carne, da enganação de seus sentidos e se consagrar à religião e à Cristo. Apesar disso, a maioria das mulheres se deixava levar pelos delitos naturalmente femininos - ligados à sexualidade - e dessa maneira se opunham à natureza masculina, mais ligada ao espírito (GONÇALVES, 2009). Para os inquisidores do século $X V$, era consenso que todas as bruxas firmavam um pacto com o diabo, por meio do qual renunciavam a fé cristã (ZORDAN, 
2005). Muitas mulheres admitiam, sob tortura, que tiveram contatos sexuais com demônios. A natureza destas relações não eram "carnais", pois os demônios são espíritos. Portanto, mesmo as que estavam em suas camas com seus maridos participavam dos sabás. Para Zordan:

...Rituais de sexo e luxúria, os sabás eram tidos como odes a Satã, festas macabras nas quais se comia carne de recémnascidos, entrava-se em transe e após danças frenéticas as bruxas copulavam com o diabo. Foram descritos como missas negras, nas quais os adeptos renegavam a fé cristã por meio do que a Inquisição supunha ser um arremedo das práticas católicas... (ZORDAN, 2005, p. 334).

Nos sabás, ritos católicos eram transfigurados em orações que violavam os principais símbolos da fé cristã. Aconteciam principalmente em dias sagrados como Natal, a Páscoa, Pentecostes e outros dias santos. Procediam dessa maneira, segundo os inquisidores, para melhor ofender o Criador e para não se impregnarem da fé cristã (ZORDAN, 2005).

\section{A violência como tema no Ensino de História: o Malleus Maleficarum}

Faz-se necessário, neste momento, tecer relações entre o objeto de estudo deste trabalho e sua importância no Ensino de História, sua contribuição para a formação humana e crítica, à conscientização e formação de identidades, que se apresentam como as novas abordagens da disciplina de História.

Partimos da ideia de que a exploração de fontes no Ensino de História se apresenta como uma estratégia viável e produtiva para se ensinar História a indivíduos que não tem como objetivo a formação como historiadores, mas para os quais os conhecimentos históricos podem fazer diferença na compreensão do mundo em que vivem e na construção de suas próprias metas de vida. Para Pereira e Seffner (2008), as sociedades que nos antecederam deixaram vestígios voluntários e involuntários, mas que, na seleção e na construção da narrativa histórica, dizem também sobre nós mesmos e marcam 
o lugar que tomamos no movimento interrupto de criação e recriação do que somos.

A partir de novas abordagens historiográficas, propostas por historiadores como Jacques Le Goff (2005) e Michel Foucault (1987), o documento passa a ser visto como monumento, ou seja, não possui mais o caráter de verdade ou falsidade creditado pelos positivistas, mas é um rastro, um indício deixado pelo passado, um constructo intencional dos homens e das circunstâncias históricas das gerações anteriores. Assim, o ofício do historiador deixa de ser a verificação da veracidade ou falsidade do documento, e passa a ser a marcação das condições políticas da sua produção (PEREIRA, SEFFNER, 2008).

Consideramos o Malleus Maleficarum como uma fonte em potencial para o estudo não só da violência mas de todo o período no qual tais práticas foram utilizadas, sendo necessário e possível a partir dele, entender o contexto social no qual foi produzido, os interesses que motivaram sua produção e o imaginário social sobre a mulher.

Como dissemos antes, a história é a um discurso sobre o passado, ou melhor, uma narrativa do passado feita a partir de fontes selecionadas seguindo critérios inerentes ao historiador. Essas escolhas são condicionadas por fatores pessoais, culturais, políticos, entre outros. As fontes, por sua vez, foram produzidas em momentos históricos também determinados pelos mesmos fatores.

É nessa perspectiva que se pretende estudar, tomando por base a exploração do Malleus Maleficarum, o período inquisitorial (séculos XII ao XIX) e as perseguições religiosas inerentes a ele.

O que os historiadores têm à sua disposição não é o passado, mas apenas uma seleção efetuada no cerne de jogos de poder e de força, atualizada pelas gerações que nos precederam e pelas circunstâncias do presente. A exploração de fontes históricas em sala de aula, entre elas o Malleus Malleficarum, coloca os estudantes diante de representações que as gerações passadas produziram sobre si mesmo e sobre os "outros", e ao mesmo tempo, estimula os alunos a elaborar uma crítica das representações que nós produzimos sobre nosso próprio passado. Portanto, ao nos dispormos a trabalhar com fontes históricas na Escola Básica, nos propomos a ensinar os estudantes a ler o passado 
através das representações que foram ou que estão sendo construídas, e através dos vestígios deixados por gerações anteriores (PEREIRA e SEFFNER, 2008).

Entre os objetivos da escola e da disciplina histórica, está o de formar cidadãos. Sujeitos capazes de historicizar a própria vida e se perceber enquanto sujeito histórico. O acúmulo de conceitos históricos serve para tornar os estudantes capazes de produzir opiniões e de considerar soluções políticas para os problemas do seu tempo. É necessário que nós professores de história reflitamos sobre como as fontes históricas podem contribuir para os objetivos expostos, e também para uma maior aproximação entre as mudanças historiográficas e a sala de aula de História.

Propomos a exploração do Malleus Maleficarum como fonte histórica, não como ilustração - pois o documento perde seu caráter de fonte e monumento, além de perdermos ricas oportunidades de interpretação - mas para abrir portas para a complexidade. Ou seja, não pensamos no documento histórico como comprovação do que diz o professor, nem para a facilitação do processo de aprendizado e conhecimento, mas sim para mostrar a complexidade que envolve as fontes, seu contexto de produção, as relações e os interesses a ela inerentes. Ensinar através de fontes históricas não significa incentivar a produção de representações por parte dos alunos, mas sim compreender como os historiadores produzem conhecimento sobre o passado a partir das fontes disponíveis, bem como os problemas implicados nessa produção.

Portanto, a exploração do Malleus Maleficarum é profícua, pois apresenta a complexidade da construção do conhecimento histórico e retira do documento o caráter de prova, deslocando o estudante do conceito de verdade que utiliza em suas práticas cotidianas e permitindo uma abordagem do relato histórico enquanto interpretação.

O Malleus Maleficarum, produzido em 1484, pelos dominicanos Heinrich Kramer e James Sprenger, funcionou como o livro de cabeceira de todos os inquisidores. Milhares de mulheres foram queimadas vivas em praça pública, diante de multidões que assistiam atentos aos espetáculos realizados pela Igreja Católica, em execuções pautadas nos pressupostos do Malleus Maleficarum. 
Autores como André Michels (2001) e Samanta Piton Vargas (2010), acreditam que o poder e alcance da Inquisição eram tão grandes que se transformaram numa histeria coletiva, se difundindo no imaginário social da Idade Média e Moderna. Como contraponto a esta ideia, Gonçalves (2009, p. 9-10) diz que "a perseguição às bruxas e aos heréticos nada tinham de histeria coletiva, mas, ao contrário foi uma perseguição muito bem calculada e planejada pelas classes dominantes, para chegar à maior centralização do poder". Assim, podemos concluir que a finalidade do Santo Ofício era manter o controle sobre a população.

Havia uma forma metódica de proceder com os interrogatórios, utilizando práticas de violência previstas e descritas no Malleus Maleficarum. Sobre a obtenção da confissão através do uso da violência:

...Sua utilidade revelou-se plenamente satisfatória quando não havia a vontade de um acusado dizer a verdade, ao menos quando esta verdade não coincidia com aquela que se desejava ouvir. Pouco importava a verdade do prisioneiro. A verdade era, apenas, a de seus algozes. Com requintes de crueldade, religiosos e oficiais do Estado quase sempre obtinham a confissão desejada... (BARROS, 1996, p. 140)

O objetivo destes interrogatórios era obter, "por livre vontade", a confissão de que os acusados eram realmente culpados. Todas as regras, formas e métodos de se proceder em relação aos acusados de bruxaria, principalmente mulheres, mas também de outros delitos espirituais foram detalhadamente descritas e analisadas, como a maneira de capturá-las, interrogá-las, condená-las e até como deveriam ser realizados os autos de fé.

Os castigos e as punições eram específicos à determinados crimes, havendo alguns específicos da Justiça Civil e outros particulares à Inquisição. Os principais métodos e recursos de violência empregados pelo Tribunal do Santo Ofício eram: a fogueira, a serra e a pêra anal para os sodomitas; a mordaça, a forquilha, a pêra oral e a destruição dos lábios e língua constituíam formas de punições aplicadas aos hereges blasfemadores, maliciosos, de falso testemunho e dissidentes religiosos; a pêra vaginal e a fogueira eram reservados às bruxas. 
Dos procedimentos citados acima, alguns eram reservados à execução durante o auto-de-fé e outros aos interrogatórios. Portanto, as confissões eram extraídas dentro de um clima de tensão e sofrimento, tanto físico quanto emocional. Procedia-se o interrogatório, procurando marcas diabólicas no corpo da acusada, como calos, cicatrizes, excesso ou ausência de dor. De acordo com Barros (1996, p. 144) os cirurgiões enfiavam longas agulhas em todos os locais do corpo, procurando tais marcas. Mesmo a marca não sendo encontrada, a acusada não estaria livre, era tida como sagaz pois conseguiu ocultar a prova de seu pacto com o mal. Para Michel Foucault:

... sujeito faz correlacionar o tipo de ferimento físico, a
qualidade e intensidade, o tempo dos sofrimentos com a
gravidade do crime, a pessoa do criminoso, o nível social de suas
vítimas. Há um código jurídico da dor; a pena, quando é
supliciante, não se abate sobre o corpo por acaso ou em bloco;
ela é calculada de acordo com regras detalhadas: números de
golpes de açoites, localização do ferrete em brasa, tempo de
agonia na fogueira ou na roda (o tribunal decide se é o caso de
estrangular o paciente imediatamente, em vez de deixá-lo
morrer, e ao fim de quanto tempo este gesto de piedade deve
intervir), tipo de mutilação a impor (mão decepada, lábios ou
língua furados). Todos esses diversos elementos multiplicam as
penas e se combinam de acordo com os tribunais e os crimes...
(FOUCAULT, 1975, p. 31)

Além da complexidade da violência institucionalizada e largamente utilizada durante os interrogatórios, Foucault chama atenção também para um elemento importante em relação à aplicabilidade das penas e dos castigos, o nível social das vítimas. É consenso que a violência e os suplícios praticados durante a Idade Média e Idade Moderna não se aplicavam de igual forma a todos os indivíduos. Dependo do grupo social ocupado, as penas poderiam ser abrandadas. Segundo Paiva, não seriam penalizados com o açoite e o degredo, por razão de privilégio de linhagem, determinados membros da nobreza e algumas profissões, como os escudeiros dos prelados e dos fidalgos, os moços da estrebaria do rei ou da rainha, os príncipes e os infantes, os duques, marqueses, condes, entre outros.

Todas estas ideias e pressupostos estão contidos no Malleus Maleficarum, que divide-se em três partes: as duas primeiras, de caráter erudito, objetivam 
esclarecer, com base na análise das Sagradas Escrituras e dos doutores oficiais da Igreja, como as bruxas são agentes do Diabo, de que forma fazem o mal, quais os limites dos seus poderes e como podem ser curados os seus malefícios e feitiçarias; já a terceira parte trata das medidas judiciais a serem tomadas contra as bruxas, tanto no tribunal eclesiástico quanto no civil. Nesta terceira parte são descritas também, as formas de instauração dos processos e os modos pelos quais devem ser conduzidos (GONÇALVES, 2009).

De acordo com Carvalho (2005), o Malleus Maleficarum foi o primeiro modelo integrado de repressão na história do Ocidente, reunindo a experiência punitiva de séculos anteriores e criando estratégias de defesa social ilimitadas. Seu discurso era baseado na potencialização da gravidade do delito, na inferioridade do delinqüente e na predestinação feminina para o crime. A mulher é naturalmente mais ligada à carne e consequentemente mais fraca que o homem. Dessa forma:

Já que o principal objetivo do diabo é corromper a fé, prefere então atacá-las... são mais impressionáveis e mais propensas a receberem influência do espírito descorporificado.. mas a razão natural está em que a mulher é mais carnal que o homem, o que se evidencia pelas muitas abominações carnais" (KRAMER e SPRENGER, 1991, p.115-116).

Todas as artimanhas atribuídas às bruxas, sortilégios, encantamentos, adivinhações, práticas de sedução, vôos noturnos, desembocam no ato carnal da junção de corpos e sexos ou na geração que lhe é conseguinte. Sucumbir aos desejos da matéria era tido como perdição para o espírito. Toda corrupção era oriunda do ato venéreo e as impossibilidades em praticar o ato carnal, conceber ou abortar após ter concebido eram considerados atos de bruxaria.

Vale ressaltar que a violência não desapareceu por completo, sua prática, sua prática ainda persiste. Pode ter sido um pouco reduzida, ou não, sendo utilizada de forma mascarada e silenciosa. Para Foucault (1975, p. 28), a violência, ou as formas de punição ainda existem em nossas sociedades, mesmo que, por vezes, não se recorram a castigos violentos ou sangrentos, mesmo quando são usados métodos mais "suaves" de trancar ou corrigir, é 
sempre do corpo que se trata, do corpo e de sua utilidade, de sua submissão. Ainda para Foucault, a sujeição do corpo não é obtida somente pelos instrumentos da violência ou da ideologia. Pode ser direta, física, sem, no entanto, ser violenta.

No ensino de história existem algumas possibilidades de se estudar a tortura relacionada à Inquisição na Europa. Mas, devido à maneira como os livros didáticos apresentam tais conteúdos, a forma como são organizados, acabam, em parte, esvaziando as possíveis abordagens do tema. As práticas de violência são mostradas como práticas mortas, que já não acontecem mais. Precisa-se, então, buscar materiais alheios ao livro didático, para complementá-lo, já que neles, os capítulos são curtos e não dão conta da complexidade do tema. Assim, é possível trabalhar em sala de aula o conceito de violência, suas manifestações e os períodos históricos nos quais ela foi e ainda é utilizada, mas apoiando-se em materiais complementares aos livros didáticos. Nesse sentido, podemos utilizar o Malleus Maleficarum como fonte para o estudo da Inquisição e da violência praticada pela Igreja; a construção da imagem da bruxa e o imaginário religioso e medieval relacionado à figura feminina. Apesar de todas essas possibilidades, optamos neste trabalho, uma proposta de discussão sobre o período inquisitorial e a violência nele ocorrida. Selecionamos o Malleus Maleficarum devido à sua relevância histórica em relação aos temas em questão.

O que se busca hoje, em todas as áreas, é uma sociedade igualitária e com mais liberdade, e essa sociedade não pode de maneira nenhuma conviver com práticas de violência. Justificamos esta pesquisa, na medida em que muitos alunos não percebem a violência como prática negativa, mas sim como uma estratégia alternativa de punição para crimes mais graves. Assim, as discussões históricas sobre a violência, tendo por base o Malleus Maleficarum, podem contribuir para a desconstrução desta postura. Portanto, a violência se apresenta como um tema importante a ser explorado na Escola Básica, pois a História, cujas finalidades são, entre outras, formar cidadãos críticos e contribuir com a formação humana, pode localizar tais práticas e discuti-las.

Quando nos dispomos a analisar determinado documento histórico, o direcionamento empregado dependerá de diversos fatores, como a natureza da 
obra, o problema de pesquisa e até mesmo a perspectiva teórica pela qual se guia o pesquisador. Segundo SÁ-SILVA, ALMEIDA e GUINDONI (2009), a riqueza de informações que podemos extrair deles justifica seu uso em sala de aula, pois possibilita ampliar o conhecimento de objetos cuja compreensão depende de contextualização. Assim, o uso e a análise de documentos e fontes em sala deve ser valorizado.

A partir da Escola dos Annales, as fontes e os documentos devem ser tratados não em uma perspectiva singular, mas como parte constituinte de um longo processo histórico. Apresenta-se também uma ampliação no conceito de documento, em que todo objeto material criado ou influenciado pelo homem pode ser utilizado como fonte histórica. Citamos como exemplo as listas de preços, os documentos contáveis, os documentos do fisco, os balanços financeiros, a documentação de compra e venda, os registros de alfândega, os arquivos notariais e paroquiais, os documentos do censo, a documentação judicial, as fontes cartoriais como os testamentos, certidões de nascimento e casamento, imagens, entre outros. Podemos citar aqui também Marc Bloch (2002), ao relacionar o ogro da história ao historiador e a necessidade da carne humana como fator determinante na pesquisa.

Dentro desta perspectiva, o Malleus Maleficarum, enquanto um grande conjunto de argumentos de ordem teológica, filosófica, histórica, jurídica e filosófica (GONÇALVES, 2011), nos apresenta múltiplas possibilidades para a discussão da violência infringida às mulheres pela Inquisição, sobretudo porque a obra contribuiu para difundir a ideia da bruxa mulher (PIMENTEL, 2012). De acordo com o documento:

...Toda bruxaria vem da luxúria carnal, na qual as mulheres são insaciáveis. Uma coisa nunca satisfeita: a boca do útero... O que é a mulher além de um inimigo da amizade... um mal da natureza, pintado com belas cores!... Quando a mulher pensa sozinha, pensa o mal, provando que tem uma natureza diferente, pois em intelecto são iguais às crianças... ela é muito mais carnal que o homem... (KRAMER, Heinrich. SPRENGER, 1995, p. 122)

É possível perceber, no excerto retirado do Malleus, as visões sobre o feminino que vigoravam durante a Idade Média e no pensamento inquisitorial, que justificava sua aproximação com o mal e a bruxaria, que por sua vez 
justificava as condenações e a violência. Inclusive, a figura da mulher aparece no Malleus Maleficarum como uma cópia imperfeita do homem, feita de uma costela torta, por isso mais propensa ao mal e ao pecado:

...convém observar que houve uma falha na formação da
primeira mulher, por ter sido ela criada a partir de uma costela
recurva, ou seja, uma costela do peito, cuja curvatura é, por
assim dizer, contrária à retidão do homem... em virtude dessa
falha, a mulher é animal imperfeito, sempre decepciona e
mente... (KRAMER e SPRENGER, p. 116).

Assim, podemos dizer que as distinções de gênero e condição social foram sendo construídas ao longo do texto, criando identidades fixas e estabelecidas generalizações que supervalorizavam as características masculinas e desclassificavam as femininas. A partir da análise do Malleus Maleficarum, abrem-se diversas possibilidades de discussão, como a violência perpetrada contra a mulher no período inquisitorial e também sua justificativa; a construção do estereótipo feminino da bruxaria; a mentalidade religiosa medieval e questões relacionadas à intolerância.

\section{Referências bibliográficas}

BARROS, R. L. de. Estado, Inquisição Moderna e tortura. Revista Saeculum, Paraíba, v. 2, p. 139-151, jul./dez. 1996.

BLOCH, M. Apologia da História ou o ofício do historiador. Rio de Janeiro: Editora Zahar, 2002.

CARVALHO, S. de. Revisita à desconstrução do modelo jurídico inquisitorial. Revista da Faculdade de Direito da UFPR, Curitiba, v. 42, n. 0, p. 35-56, abril 2013.

FOUCAULT, M. A arqueologia do saber. Rio de Janeiro: Forense Universitária, 1987.

. Vigiar e Punir. Petrópolis: Editora Gallimard, 1975.

GINZBURG, C. Mitos, emblemas, sinais: morfologia e história. São Paulo: Companhia das Letras, 1990.

. O inquisidor como antropólogo. Revista Brasileira de História, São Paulo, v. 01, n. 21, p. 9-20, set./fev. 1990-1991. 
GONÇALVES, B. G. de O. O mal da bruxaria. XXVI Simpósio Nacional de História, 2011, São Paulo. Anais do XXVI Simpósio Nacional de História. v. 1. São Paulo, 2011 São Paulo, julho 2011. p. 1-17.

GONÇALVES, F. de S. O clericalismo na literatura: a cópula do feminino e o diabólico, um vislumbre da imagem precursora da bruxa em A demanda do Santo Graal. Revista Veredas da História, Rio de Janeiro, v. 2, n. 1, p. 1-25, jan./fev. 2009.

KRAMER, H. SPRENGER, J. Malleus Malleficarum: O martelo das feiticeiras. Rio de Janeiro: Editora Rosa dos Tempos, 1995.

LE GOFF, J. A História Nova. São Paulo: Martins Fontes, 2005.

MICHELS, A. Histeria e feminilidade. Revista Ágora. Rio de Janeiro, v. 4 n. 1, p. 33-51, jan./jun. 2001.

PAIVA. M. de. Crime e Castigo: as civilizadas práticas jurídicas de uma Idade Moderna. Revista Acervo. Rio de Janeiro, v. 15, n. 1, p. 79-94, jan./jun. 2002.

PEREIRA, N. M. SEFFNER. O que pode o Ensino de História? Sobre o uso de fontes na sala de aula. Revista Anos 90. Porto Alegre, vol. 15, n. 28, p. 113128, dez. 2008

PIMENTEL, H. U. Demonologia, bruxas e estereótipos. Revista Trilhas da História. Três Lagoas, v.1, n. 2, p. 33-54, jan/jun, 2012.

SÁ-SILVA, J. R. ALMEIDA, Cristóvão Domingos de. GUINDANI, Joel Felipe. Pesquisa Documental: pistas teóricas e metodológicas. Revista Brasileira de História \& Ciências Sociais. Rio Grande do Sul, Ano 1, n. 1, p. 1-15, julho 2009.

VARGAS, S. P. Inquisição na Espanha: desde o antijudaísmo na Antiguidade à perseguição dos conversos na Idade Moderna. Revista Historiador Especial. Porto Alegre, Ano 3, n. 1, p. 161-178, julho 2010.

ZORDAN, P. B. M. B. G. Bruxas: figuras de poder. Revista Estudos Feministas. Rio Grande do Sul, v. 3, n. 2, p. 331- 341, mai./ago. 2005. 